\title{
EVALUATION OF INVERSION STRENGTHS AND MIXING HEIGHTS DURING EXTREMELY STABLE ATMOSPHERIC STRATIFICATION
}

\author{
Ari Karppinen, Sylvain M. Joffre,Jaakko \\ Kukkonen and Pia Bremer \\ Finnish Meteorological Institute \\ Sahaajankatu 20 E, FIN - 00810 Helsinki, Finland \\ Fax +358 91929 5403, Email: Ari.Karppinen@fmi.fi
}

\begin{abstract}
We have compiled data from Finnish sounding stations and classified the inversions according to their total depth and the stability of the boundary layer. We studied the persistence of the inversions and the influence of cloudiness and wind speed on the temperature gradient. Additionally, we addressed the specific problems of an urban area, using measurements from a meteorological mast situated in the Helsinki metropolitan area by comparing them to those from the radiosonde profiles at the rural site of Jokioinen. We also compared several common schemes for the height of the stable boundary layer to results from our own FMI-method. Based on this analysis a modification to the FMI method was suggested.
\end{abstract}

Keywords: Surface inversion, stable boundary layer, mixing height

Reference to this paper should be made as follows: Karppinen, A., Joffre, S. M. , Kukkonen, J. and Bremer P. (2001) 'Evaluation of inversion strengths and mixing heights during extremely stable atmospheric stratification', Int. J. Environment and Pollution, Vol. 16, No. 1-6, pp. xx-xx.

\section{Introduction}

This work is related to the COST 715 action "Meteorology applied to urban air pollution problems". A review of activities in this action presented elsewhere in this conference (Fisher et al., 2000).

Meteorological factors have a substantial influence on the atmospheric dispersion of air pollution. Dispersion is particularly affected by the wind speed and direction, atmospheric turbulence and the occurrence of inversion layers, ambient temperature and the mixing height (for instance, Kukkonen et al., 1999).

The most unfavourable weather situations for air quality are related with stagnating anticyclones. During an anticyclone, the winds are light and the lowest part of the atmosphere can be very stable. In very unfavourable weather conditions, even average traffic volumes are sufficient to maintain an air quality episode. However, only a small fraction of the anticyclone situations leads to episodic conditions (Mäkelä et al., 1998). 
In Northern European conditions, the formation of a severe air pollution episode requires a strong ground-based inversion, by which cold air near the ground surface is blocked under the warmer air layer above. Particularly emissions from road traffic are then poorly dispersed. Emissions from tall stacks of e.g. heating plants may be emitted above the inversion height, and these therefore do not influence substantially pollution near the ground level.

In this paper, we present results from a climatological study of surface inversions based on a dataset from three Finnish sounding stations. The inversions were characterised according to their total depth and the stability of the boundary layer, which was straightforwardly estimated directly from the temperature gradient in the layer from the ground up to 100 meters. Further, we studied the persistence of the inversions as well as the influence of cloudiness and wind speed on the temperature gradient .

Secondly, we investigated how these inversion statistics at rural sites apply to the specific problems of an urban area, using measurements from a meteorological mast situated in the Helsinki metropolitan area. These measurements are compared to those from the radiosonde profiles at the rural site of Jokioinen in Southern Finland. We particulary analysed temperature inversions with a potential temperature gradient larger than $0.10^{\circ} \mathrm{C} / \mathrm{m}$, which are predominantly observed during winter nights. Finally, we analysed the behaviour of the meteorological pre-processing model FMI-MPP (Karppinen et al., 1997) utilising this experimental database. Other commonly used schemes for determining the height of the stable boundary layer, reported by Fisher et al. (1998), were also tested against the FMI-method and against each other. Based on this analysis a modification is suggested to the FMI-MPP method.

\section{Measurements}

Our empirical analysis is based on aerological data collected during the years 19891996 from three Finnish sounding stations (with 2 soundings /day) and on meteorological data collected during the years 1989 -1998 from a 330-m mast in Kivenlahti in the Metropolitan area of Helsinki (Figure 1).

The mast data consists of measurements of measurements of the following parameters (collected every 10 minutes):

Wind speed (min,max,average)

Temperature(average)

Wind direction (min, max, average) and

relative humidity (average) at heights of $26,91,182,327 \mathrm{~m}$ at heights of 5, 26, 48, 91, 142,182, 266, $296 \mathrm{~m}$

at heights of 26, 91, 182 and 296 meters. 

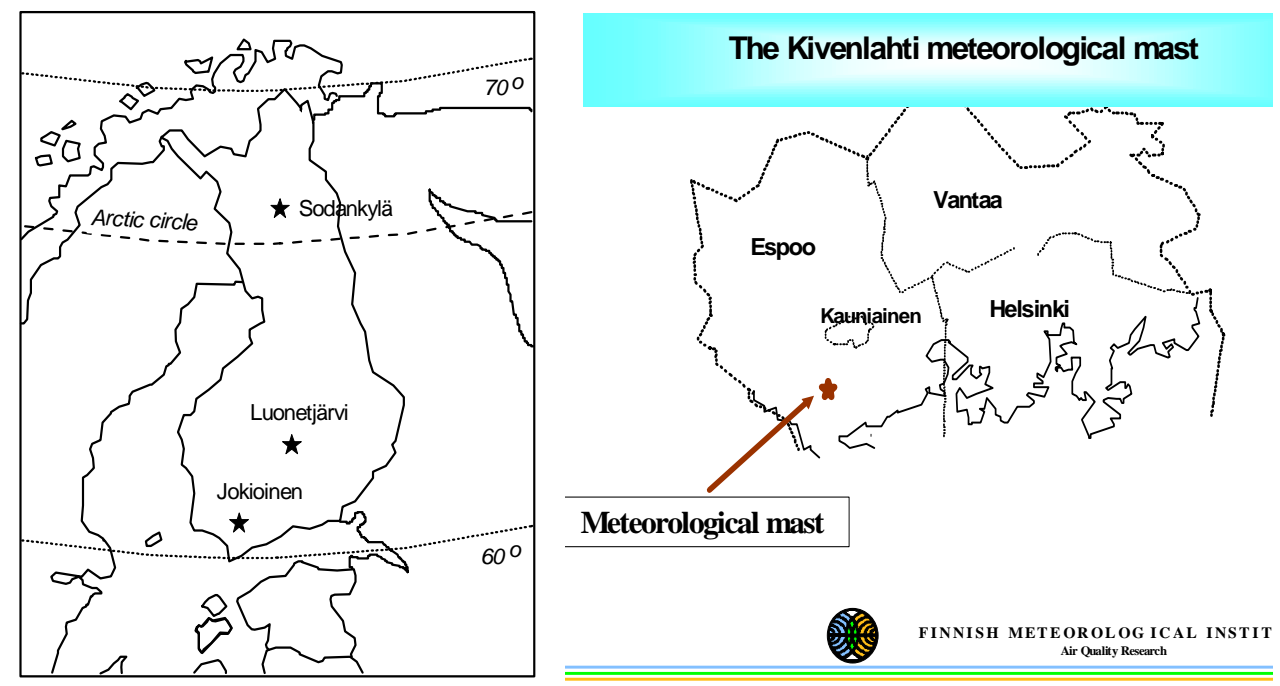

Figs 1a-b. Locations of the experimental sites

In this paper we analyse the measurements at the heights of 26 and 91 meters and the corresponding temperature and wind speed profiles. The aerological data from the radiosonde stations are from routine archives and sampled with a typical vertical resolution of 50 - 200 metres

\section{Results}

The ground-based inversions are substantially more critical for pollution from lowlevel sources, compared with inversions at upper levels. Figures 2a-f present the frequency of ground-based inversions at the three stations for the year 1996.

The inversions in Figures $2 \mathrm{a}-\mathrm{f}$ have been categorised into two classes according to their strength, i.e., the temperature difference between the top of the inversion and the ground. By definition, the strength of the moderate and strong inversions are $0.1-10^{\circ} \mathrm{C}$ and larger than $10^{\circ} \mathrm{C}$, respectively. Due to the poor vertical resolution of the soundings it is possible that some strong inversions are classified incorrectly as modest inversions so the percentage of strong inversions presented here represents a lower limit of the actual percentage of strong inversion. The strong inversions have a substantially more important effect on air quality, compared with the moderate inversions.

Figures $2 \mathrm{a}-\mathrm{f}$ show that ground-based inversions are common in Finland. At midnight, these prevail from approximately 20 to $80 \%, 15-95 \%$ and $10-90 \%$ of the time at the stations of Sodankylä, Luonetjärvi and Jokioinen, respectively, on a monthly basis. At noon, the corresponding frequencies are clearly smaller, smaller than approximately $60 \%$, $40 \%$ and $20 \%$ of the time at the stations of Sodankylä, Luonetjärvi and Jokioinen, respectively. 

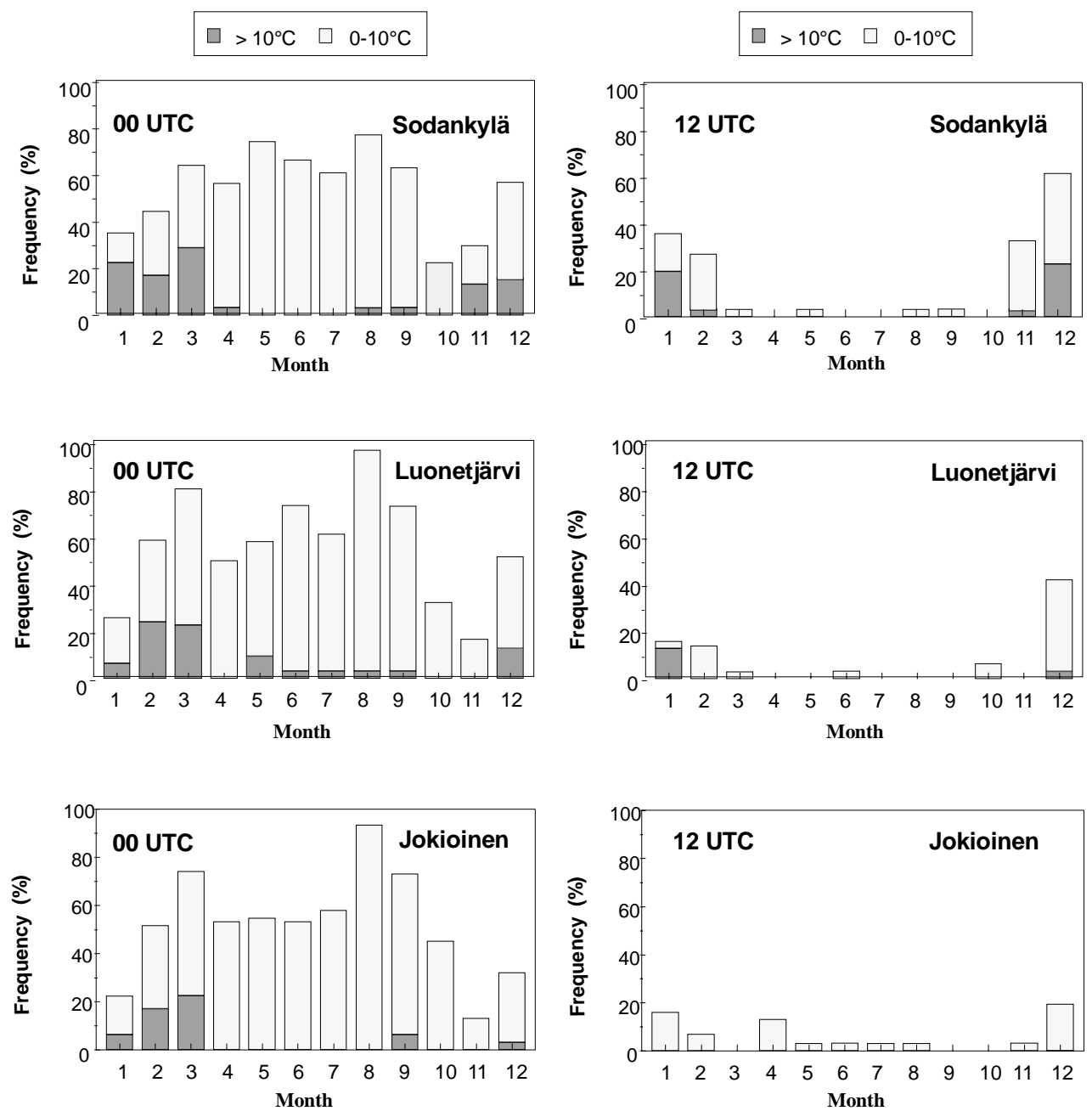

Figs 2a-f. The frequency of ground-based inversions at midnight (00 UTC) and at noon (12 UTC) at the stations of Jokioinen, Luonetjärvi and Sodankylä in 1996. The strong and moderate inversions, having a temperature change larger than $10^{\circ} \mathrm{C}$ and $0.1-10{ }^{\circ} \mathrm{C}$, respectively, have been shown separately.

The strong inversions have a seasonal variation at all the stations considered. At the northernmost station of Sodankylä, the strong inversions occur in winter and in late autumn both at midnight and at noon, while at the southernmost station of Jokioinen only at midnight. The frequency of strong inversions grows substantially when moving from southern Finland to the northern parts of the country.

The fraction of extremely strong inversion $\left(>18{ }^{\circ} \mathrm{C}\right)$ of all the studied cases was $0.2 \%$ at Jokioinen, $1 \%$ at Luonetjärvi and $2 \%$ at Sodankylä. 
Evaluation of inversion strengths and mixing heights during extremely stable atmospheric stratification

\begin{tabular}{llllllll}
\hline & Oct & Nov & Dec & Jan & Feb & Mar & Apr \\
\hline Jokioinen & 0 & 0 & 0.5 & 0 & 0.9 & 0 & 0 \\
Luonetjärvi & 0 & 0 & 0.9 & 1.6 & 3.1 & 0 & 0 \\
Sodankylä & 0.9 & 3.3 & 3.7 & 6.1 & 7.5 & 2.4 & 0 \\
\hline
\end{tabular}

Table 1. The fraction of extremely strong inversions $\left(>18^{\circ} \mathrm{C}\right)$ at the Finnish sounding stations. (winter time 1989-1996: 00 UTC )

\section{Duration of the inversions}

A study of the occurrence of persistent surface inversions (observed at least during 2 successive soundings) was performed using data for the year 1996. The results presented in Table 2 indicate that strong inversions prevailing more than 3 days are observed only in Sodankylä during the winter months.

\begin{tabular}{|c|c|c|c|c|}
\hline \multirow[t]{2}{*}{ Month } & \multicolumn{2}{|c|}{ Jokioinen } & \multicolumn{2}{|c|}{ Sodankylä } \\
\hline & dura & & durat & \\
\hline \multirow[t]{3}{*}{ Jan } & 0.5 & 1 & 0.5 & 3 \\
\hline & 1 & 1 & 2 & 1 \\
\hline & - & - & 4 & 1 \\
\hline \multirow[t]{2}{*}{ Feb } & 0.5 & 1 & 0.5 & 1 \\
\hline & 1 & 1 & 5.5 & 1 \\
\hline Mar & - & - & 0.5 & 1 \\
\hline \multirow[t]{2}{*}{ Apr } & 0.5 & 1 & - & - \\
\hline & 3 & 1 & - & - \\
\hline May & - & - & 1 & 1 \\
\hline Jun & - & - & - & - \\
\hline Jul & 0.5 & 1 & - & - \\
\hline Aug & 1 & 1 & 0.5 & 1 \\
\hline Sep & - & - & 1 & 1 \\
\hline Oct & - & - & - & - \\
\hline \multirow[t]{2}{*}{ Nov } & - & - & 0.5 & 1 \\
\hline & - & - & 1.5 & 3 \\
\hline \multirow[t]{5}{*}{ Dec } & 0.5 & 2 & 0.5 & 1 \\
\hline & 1 & 2 & 1.5 & 1 \\
\hline & - & - & 4 & 1 \\
\hline & - & - & 4.5 & 1 \\
\hline & - & - & 5 & 1 \\
\hline
\end{tabular}

Table 2. Occurrence of surface inversions lasting more than 12 hours at Jokioinen and Sodankylä (1996). 


\section{Influence of cloudiness and wind speed on the inversions}

A more detailed analysis of the available meteorological data shows that the strong inversions are usually radiational inversions caused by cooling of the ground by outgoing long-wave radiation. Strong radiative inversions are commonly formed in conditions of low wind speed and low cloudiness. This fact is illustrated in Figs. 3a-b. where the average cloudiness and wind speed are classified according to the observed temperature gradient. The profile classification according to the estimated temperature gradient $\left({ }^{\circ} \mathrm{C} / 100 \mathrm{~m}\right)$ which we will use from this point on, is not directly comparable to classification based on inversion depths. The temperature gradient is however the crucial parameter in the method used routinely at FMI for stable mixing height calculation whereas there is no simple realtionship between the SBL depth and the depth of the surface inversion layer (Caughey,1982).
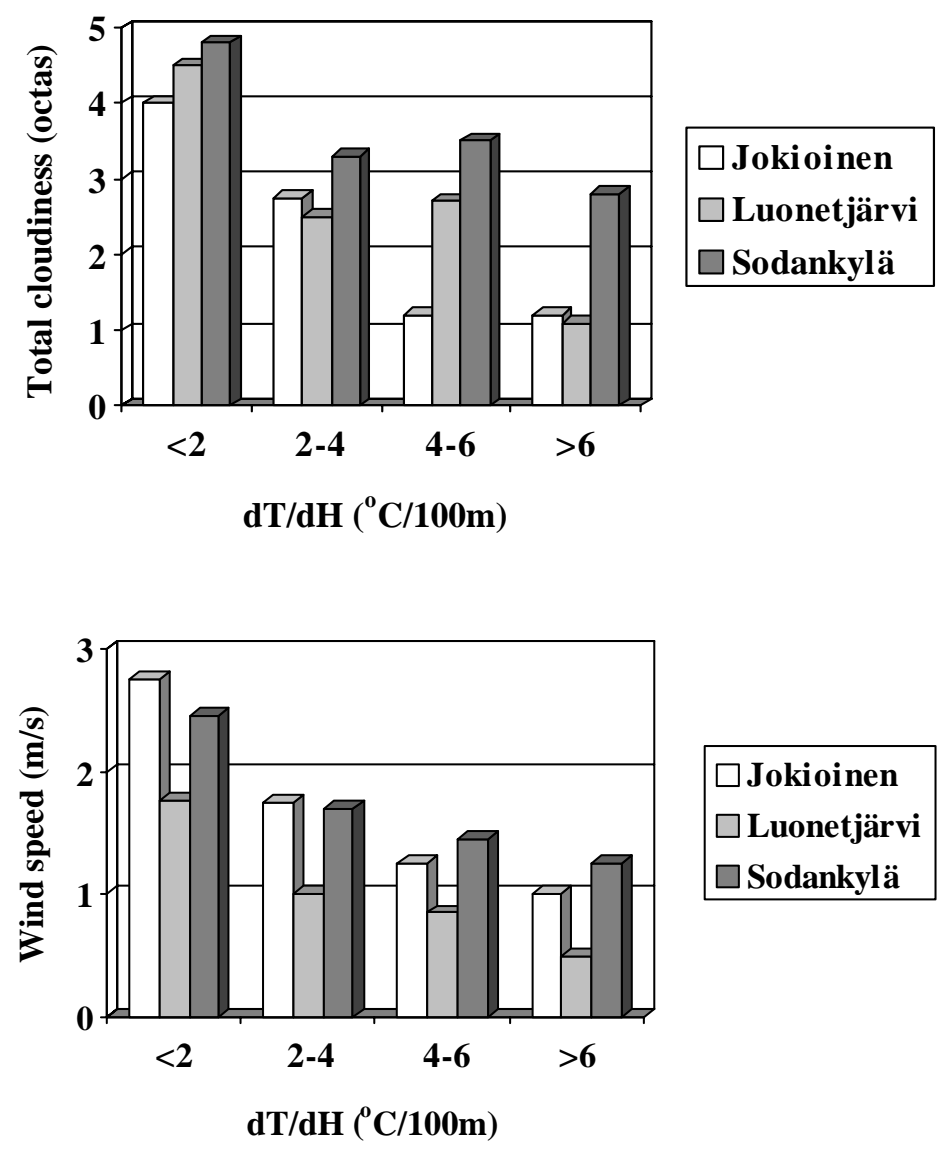

Figs 3a-b. Total cloudiness and average wind speed in different temperature gradient classes at the radiosounding stations of Jokioinen $\left(60^{\circ} 49^{\prime} \mathrm{N}\right)$, Luonetjärvi $\left(62^{\circ} 24^{\prime} \mathrm{N}\right)$ and Sodankylä $\left(67^{\circ} 22^{\prime} \mathrm{N}\right)$. 
Evaluation of inversion strengths and mixing heights during extremely stable atmospheric stratification

\section{Kivenlahti meteorological mast}

In order to investigate how the previous statistics obtained at rural sites can be transferred to the metropolitan area of Helsinki (ca. 800000 inhabitants), we looked at meteorological data obtained from a high mast in the suburban part of Helsinki (Fig.1). We analysed the temperature and wind data measured at the heights of 26 and 91 meters. Figure 4 presents the distribution of temperature differences for all the studied stable cases having a temperature inversion. The temperature gradient is scaled to represent a temperature difference over 100 meters from the using the measured temperature difference between the heights of $28 \mathrm{~m}$ and 91 meters. It can be immediately seen that the vast majority of stable cases fall in the inversion category of temperature gradient less than $6{ }^{\circ} \mathrm{K} / 100 \mathrm{~m}$. Integrating the distribution function we notice that about $20 \%(10000$ cases) of the studied temperature inversions are greater than $4{ }^{\circ} \mathrm{K} / 100 \mathrm{~m}$ and only $6 \%$ ( 2500 cases) of the temperature gradients are greater than $6{ }^{\circ} \mathrm{K} / 100 \mathrm{~m}$

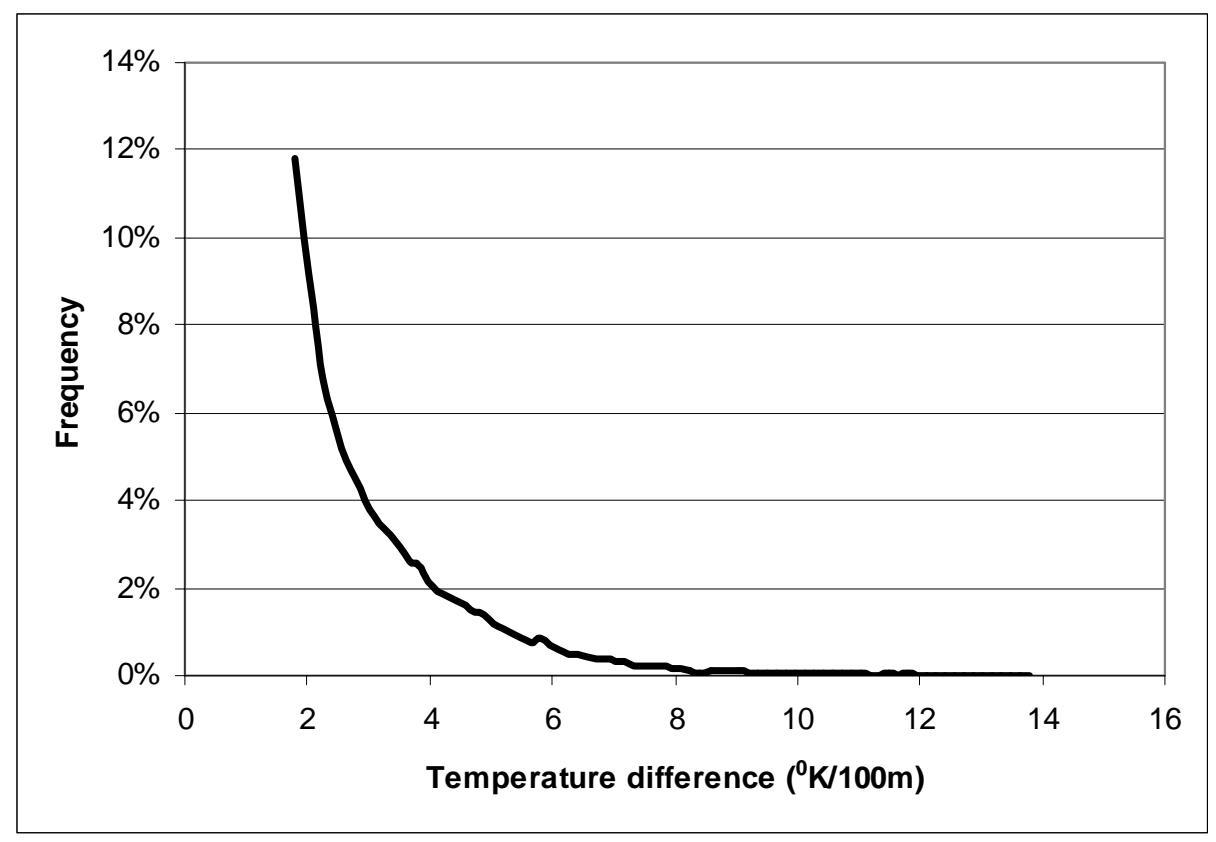

Figure 4 . The frequency distribution of the potential temperature differences $\left({ }^{0} \mathrm{~K} / 100 \mathrm{~m}\right)$ estimated from mast measurements at $26 \mathrm{~m}$ and $91 \mathrm{~m}$ at Kivenlahti, 1989-1998.

\section{Mixing height}

The surface inversion depths or temperature gradients are quite useful in describing and classifying the stable meterological conditions but for dispersion modelling applications we have also to evaluate the mixing height, which is here defined as the height of the layer adjacent to ground over which pollutants emitted within this layer of entrained into it become vertically dispersed within a time scale of about an hour (Fisher 
et al., 1998). Unfortunately the reliable mixing height determination under all conditions is still an unsolved problem. Furthermore, in our study area we do not have any remote sounding methods available so we have to estimate the mixing height using the profile measurements, mast measurements at Kivenlahti and radiosonde at Jokioinen. A critical evaluation of the use of these methods in mixing height determination can be found in Fisher et al., 1998.

We used four different schemes for calculating the stable mixing height. The method used routinely at FMI for stable mixing height calculation (Karppinen, et al,1998) uses only the potential temperature gradient to estimate the stable mixing height $\mathrm{h}$ :

$$
h=\frac{4.5}{g_{1}+0.005} ; \quad g_{1}=\frac{\left(\theta_{2}-\theta_{1}\right)}{\left(z_{2}-z_{1}\right)} ; \mathrm{g}_{1}>0.01^{\circ} \mathrm{K} / \mathrm{m}
$$

where $\theta_{1}$ and $\theta_{2}$ are the potential temperatures measured at levels $\mathrm{z}_{1}$ and $\mathrm{z}_{2}$.

The three other methods are widely used diagnostic relations for evaluating the height of the stable mixing layer (Fisher et al., 1998).

A classical scheme derived by using similarity considerations and scaling arguments:

$h=c_{2} \sqrt{\frac{u_{*} L}{f}} \quad, c_{2}=0.35 \quad$ (constant $c_{2}$ from Joffre, 1981)

where $\mathrm{u} *$ is the fricition velocity, $\mathrm{L}$ is the Monin-Obukhov length and $\mathrm{f}$ the Coriolis parameter.

A simple scheme connecting directly the Monin-Obukhov length and mixing height:

$h=c_{3} L, \quad c_{3}=2, \quad$ (constant $c_{3}$ from Kitaigorodskii and Joffre, 1988)

and finally an interpolation scheme between near neutral and very stable conditions

$h=\frac{u_{*}}{f}\left(\frac{1}{\Lambda_{0}}+\frac{\sqrt{\mu}}{\kappa C_{h}}\right), \mu=\kappa u_{*} /(f L), \Lambda_{0}=0.3, C_{h}=0.85 \quad$ (Zilitinkevich, 1989)

Table 3 presents the basic statistics of the calculated mixing height with the different schemes. It should be noted that for the classical scheme and for the simple MO-scheme there has been a very wide spread in the proposed constants in Eqs. (2-4).

If we choose the constant $c_{2}$ in Eq.(2) to be $c_{2}=0.4$ as proposed by Garratt (1982) and Brost and Wyngaard (1978) instead of the value $c_{2}=0.35$ (Joffre,1981) which was used in these calculations we get identical mean values with the Zilitinkevich interpolation scheme (Eq. 4). Correspondingly, if we would like the mean value of the simple MOscheme to equal the mean of Zilitinkevich interpolation scheme we would need to choose $c_{3}=0.9$ which is clearly a lower value than is presented in the literature. 
Evaluation of inversion strengths and mixing heights during extremely stable atmospheric stratification

\begin{tabular}{lccccc}
\cline { 2 - 5 } & FMI-Jokioinen & FMI-Kivenlahti & $\begin{array}{c}\text { Classical } \\
\left(\mathrm{c}_{2}=0.35\right)\end{array}$ & $\begin{array}{c}\text { MO-simple } \\
\left(\mathrm{c}_{3}=2\right)\end{array}$ & $\begin{array}{c}\text { Zilitinkevich } \\
\text { interpolation }\end{array}$ \\
\cline { 2 - 6 } Mean & 201,10 & 175,37 & 209,36 & 558,06 & 242,11 \\
Standard Error & 0,71 & 0,30 & 0,71 & 2,42 & 0,77 \\
Median & 164,00 & 175,00 & 165,00 & 385,00 & 197,00 \\
Standard Deviation & 153,29 & 64,27 & 153,57 & 524,18 & 166,80 \\
Range & 2450,00 & 239,00 & 1380,00 & 4948,00 & 1465,00 \\
Minimum & 50,00 & 33,00 & 22,00 & 52,00 & 27,00 \\
Maximum & 2500,00 & 272,00 & 1402,00 & 5000,00 & 1492,00 \\
Count & 46951 & 46951 & 46951 & 46951 & 46951 \\
\hline
\end{tabular}

Table 3. Statistical parameters of the different mixing height schemes.

From Table 4 we can see that the results from all three diagnostic mixing height formulas corralate nearly perfectly with each other and that the FMI-scheme for the Kivenlahti site has a moderate correlation with the diagnostic schemes. On the other hand the mixing height calculations using the Jokioinen-observatory data does not have any correlation with the diagnostic schemes and only a weak correlation with the mixing height estimates calculated with the same scheme but using the Kivenlahti data. This is obviously due to the fact that the FMI scheme doesn't use any information about the wind profile in estimating the mixing height whereas all the other schemes utilise also the measured wind speeds. That also explains the good correlation between the three other schemes; as the physics of the schemes is nearly identical also the results are expected to be very similar.

\begin{tabular}{cccccc}
\hline & FMI-Jokioinen & FMI-Kivenlahti & Classical & MO-simple & Zilitimkevich \\
\hline FMI-Jokioinen & 1 & & & & \\
FMI-Kivenlahti & 0,247 & 1 & & & \\
Classical & 0,072 & 0,396 & 1 & & \\
MO-simple & 0,087 & 0,469 & 0,981 & 1 & \\
Zilitinkevich & 0,066 & 0,367 & 0,998 & 0,968 & 1 \\
\hline
\end{tabular}

Table 4. Correlations between the different mixing height schemes.

The weak correlation between FMI-Jokioinen and FMI-Kivenlahti (same FMI-scheme using radiosonde profiles at Jokioinen and mast profiles at Kivenlahti respectively) calculations was further studied by dividing the data according to wind direction into 12 sectors. Figure 5 presents the partial correlations in each of the wind sectors. It is observed that the correlation is the weakest for southerly (from the sea) winds which is quite much an expected result as the Jokionen observatory is located $100 \mathrm{~km}$ north from 
the seaside so the effect of the sea is not observed in the mixing heights calculated using the soundings at Jokioinen. The most urbanised area is located in the easterly direction and the corresponding correlation is also observed to be very low.

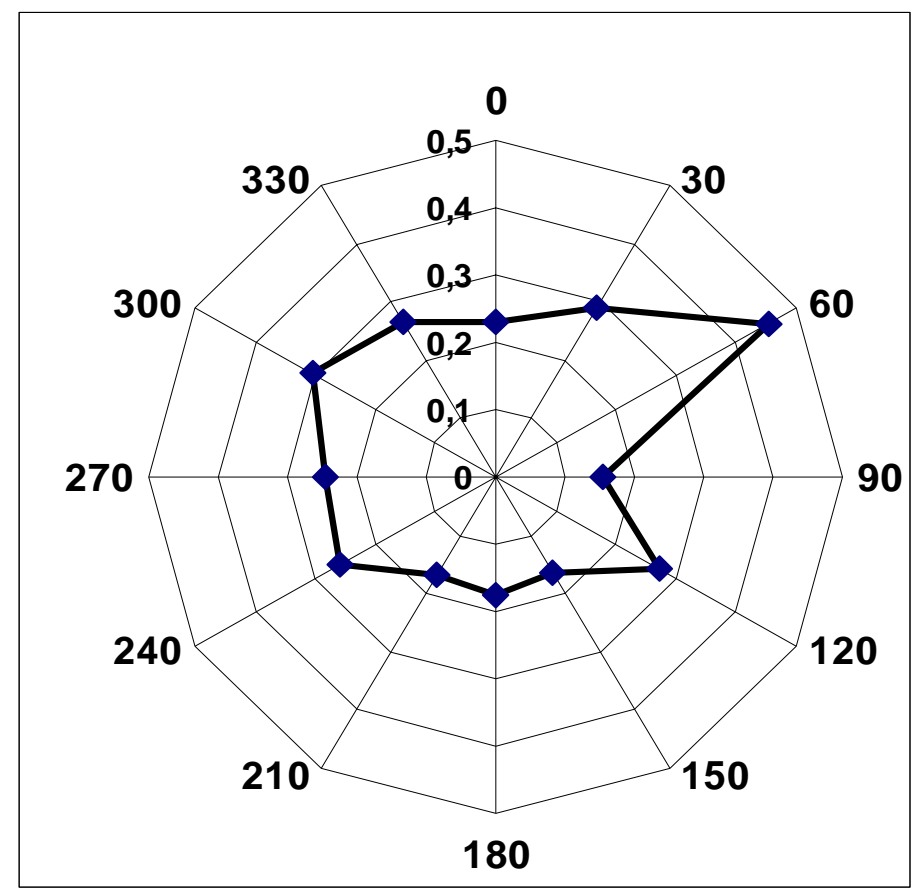

Figure 5. Correlation between the calculated mixing heights (FMI scheme) using Jokioinen and Kivenlahti data.

The clear dependence of the comparison results on the wind direction suggests that for a nonhomogeneous area it should be advisable to include the information on measured wind speeds on into the FMI-scheme. The simplest way to include it in the stable mixing height formula (eq.1) is to use directly the measured difference of wind speeds $\Delta \mathrm{U}$ at the two heights :

$h=c \frac{\Delta U}{g_{1}+0.005}, c=1.8 \mathrm{Ks} / \mathrm{m}$

If we evaluate the averages of calculated mixing heights in different wind direction sectors (figure 6), we note that the means of the two original FMI-schemes differ in the southerly wind sectors which once again confirms the result that the effect of the sea is not observed in the Jokioinen soundings.

The Zilitinkevich interpolation scheme gives clearly higher mixing heights than the simple temperature gradient based FMI-scheme in the most urban and rough wind directions (Karppinen et al, 2000) which clearly suggests that for rough and urban areas the different schemes give rather differing estimates for the height of the stable boundary 
Evaluation of inversion strengths and mixing heights during extremely stable atmospheric stratification

layer. However, in the smooth, non-urban sectors, the averages of the calculated mixing heights are very similar. The modified FMI-scheme gives very similar results with the Zilitinkevich interpolation scheme and also the correlation of the time-series of calculated mixing heights with the Zilitinkevich scheme is good (the correlation coefficient $=0.90$ ).

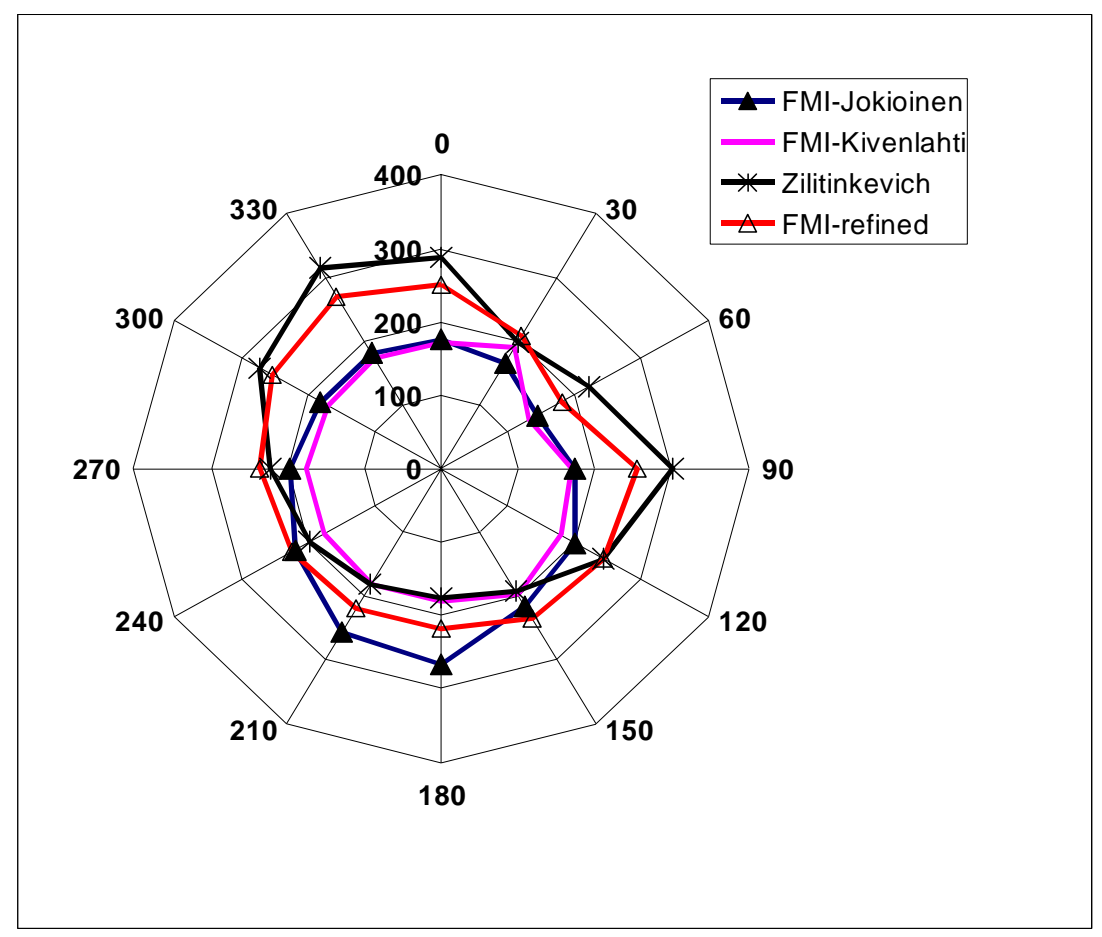

Fig. 6. The dependence of the mean of the calculated mixing height on wind direction.

\section{Conclusions}

We presented results from a climatological study of surface inversions based on a dataset from three Finnish sounding stations. The inversions were characterised according to their total depth and the stability of the boundary layer, which was straightforwardly estimated directly from the temperature gradient in the layer from the ground up to 100 meters. Further, we studied the persistence of the inversions as well as the influence of cloudiness and wind speed on the temperature gradient.

Secondly, we investigated how these inversion statistics at rural sites apply to the specific problems of an urban area, using measurements from a meteorological mast situated in the Helsinki metropolitan area. These measurements were compared to those from the radiosonde profiles at the rural site of Jokioinen in Southern Finland. We particulary analysed temperature inversions with a potential temperature gradient larger than $0.10^{\circ} \mathrm{C} / \mathrm{m}$, which are predominantly observed during winter nights.

Finally, we analysed the behaviour of the meteorological pre-processing model FMI, utilising this experimental database. Other commonly used schemes for determining the 
height of the stable boundary layer were also tested against the FMI-method and against each other.

Based on this analysis a modification is suggested to the FMI-MPP method. The modified FMI-scheme gives very similar results with the Zilitinkevich interpolation scheme and also the correlation of the time-series of calculated mixing heights with the Zilitinkevich scheme is good.

\section{References}

Brost, R.A. and Wyngaard, J.C. (1978), A model study of the stably stratified planetary boundary layer. J. Atmos. Sci. 35, 1427-1440.

Caughey, S. J. (1982), Observed characteristics of the atmospheric boundary layer. In: F.T.M. Nieuwstadt and H. van Dop (eds.) : Atmospheric Turbulence and Air Pollution Modeling. Dordrecht-Boston-London: Reidel Publ. Co., 107-158.

Fisher, B.E.A, Erbrink, J.J., Finardi, S , Jeannet, P., Joffre, S., Morselli, M.G., Pechinger, U., Seibert, P. and Thompson, D.J. (eds.) (1998), COST Action 710 - Final Report. Office for Official Publications of the European Communities, Luxembourg.

Fisher, B.E.A., Kukkonen, J. and Schatzmann, M. (2000), Meteorology applied to Urban Air Pollution Problems COST 715. International Journal of Environment and Pollution (in print).

Garratt, J.R. (1982), Observations in the nocturnal boundary layer. Boundary-Layer Meteorol. 22, 21-48.

Joffre, S. S. (1981), The physics of the mechanically driven atmospheric boundary layer as an example of air-sea interaction. Univ. of Helsinki, Dept. of Meteorol. Rep. No.20, 75 pp.

Karppinen, A., Joffre, S. and Vaajama, P. (1997), Boundary layer parameterisation for Finnish regulatory dispersion models. International Journal of Environment and Pollution. 8, Nos. 36, p. 557-564.

Karppinen, A., Kukkonen, J., Nordlund, G., Rantakrans, E., and Valkama, I. (1998), A dispersion modelling system for urban air pollution. Finnish Meteorological Institute, Publications on Air Quality. Helsinki, $58 \mathrm{p}$.

Karppinen, A., Joffre, S. M. and Kukkonen, J. (2000), The refinement of a meteorological preprocessor for the urban environment

Kitaigorodskii, S. A.; Joffre, S. M. (1988), In search of a simple sacling for the height of the stratified atmospheric boundary layer. Tellus 40A, 419-433.

Kukkonen, J., Konttinen, M., Bremer, P., Salmi, T. and Saari, H. (1999), The seasonal variation of urban air quality in northern European conditions. International Journal of Environment and Pollution, (in print).

Mäkelä, K., Estlander, K. and Kukkonen, J. (1998), Air pollution episodes in Finnish cities, $\underline{\text { Nordic }}$ Road \& Transport Research. 10, No. 1, pp. 4-6.

Zilitinkevich, S. S. (1989), Velocity profiles, the resistance law and the dissipation rate of mean flow kinetic energy in a neutrally and stably stratified planetary boundary layer. BoundaryLayer Meteorology, 46, 367-387. 